\title{
Do estado territorial ao estado de direito - uma abordagem das relações internacionais
}

\author{
Marcela Tomaz
}

\section{Resumo}

Este artigo propõe uma reflexão acerca da constituição dos Estados Nacionais a partir da radicalização dos princípios estabelecidos no Tratado de Westphália (1648), relacionados aos preceitos de não intervenção e de soberania, prevalecendo em todo o direito internacional um sistema laico de relações internacionais. A partir desses princípios, percebe-se que o Estado só é soberano por completo e independente em assuntos internos e externos, dentro de seu território, delimitado pelas fronteiras nacionais. Por isso, reitera o fortalecimento de seus limites, enaltecendo seu poder e sua jurisdição. Tanto Estado quanto soberania constituem conceitos dinâmicos, e não estáticos, e é compreensível que eles acompanhem as mudanças estruturais dos sistemas políticos e econômicos internacionais. Neste trabalho será analisado também o conceito de migrações internacionais, a partir do qual os migrantes constituem a dimensão problematizadora do processo de globalização, já que, na maioria das vezes, seus direitos fundamentais são ignorados. Assim, os instrumentos internacionais de proteção aos direitos humanos apresentam natureza subsidiária, pois atuam como garantias adicionais de proteção, após falharem os sistemas nacionais.

Palavras-chave: Estados Nacionais. Fronteiras. Migrações Internacionais. Direitos Humanos.

\section{Introdução}

A disciplina Relações Internacionais é a mais recente dentre as Ciências Sociais, sendo considerada por muitos autores como um ramo da Ciência Política. Seu estudo desenvolveu-se no século XX, a partir do período entre-guerras (FARO,

\footnotetext{
${ }^{1}$ Graduanda em Relações Internacionais do Centro Universitário de Brasília - UniCEUB. E:mail: marcelinhatomaz@hotmail.com
} 
2001) e esteve intimamente ligada aos próprios desdobramentos do contexto internacional, visto que as teorias foram elaboradas para responder as preocupações e problemas vividos em cada época, caracterizada, assim, por um sistema conceitual referido necessariamente a contextos bem marcados. Conforme afirma Cox, "as teorias são sempre para alguém e para algum propósito" (COX, 1986, p. 207).

Seu desenvolvimento intelectual como disciplina indica que essa foi, em grande parte, determinada e guiada pelas exigências da realidade internacional. As preocupações de ordem e de segurança acabaram prevalecendo sobre debates mais críticos e análises das estruturas das relações domésticas e internacionais, nas quais as relações atravessam as fronteiras e envolvem atores estatais e não estatais.

Surgiu com o objetivo de, por meio do estudo científico, estabelecer as condições para uma paz duradoura e uma cooperação crescente entre os Estados, portanto, com um forte conteúdo normativo, baseado na crença de que a pesquisa deve ter como objetivo retratar as condições da realidade.

Mesmo com forte carga de normatização, o debate metodológico das Relações Internacionais acerca da imparcialidade não pode ser considerado neutro ou desprovido de valores, já que fazer ciência requer um método e uma explicação para os resultados obtidos, e o debate acerca do lugar da subjetividade na construção do conhecimento, no pós-Guerra Fria, acabou passando ao largo dos debates mais importantes da Teoria das Relações Internacionais. O fato de não existirem verdades absolutas, mas pontos de vista defensáveis, faz com que percebamos a Teoria das Relações Internacionais não como a guardiã de verdades imutáveis, mas pelo contrário, como uma busca de explicações e de interpretações, de revisão e de reavaliação de seus resultados, apesar de sua falibilidade e de seus limites (CERVO; BERVIAN, 2002). A própria construção da realidade é baseada na interpretação dos fatos, agentes e estruturas que são co-constituídos.

O assim chamado progresso, igualmente como a realidade, é construído. As estruturas não são e não estão pré-definidas. As teorias foram usadas historicamente com o objetivo de direcionar o comportamento, mas não podem prever, com certeza, fatos que virão a acontecer. Os instrumentos de trabalho das ciências sociais não são leis e sim construções. É preciso entender, interpretar e contextualizar os fatos sociais e internacionais. 
A Teoria das Relações Internacionais procura descrever os fundamentos políticos relativos à estruturação da ordem internacional (FARO, 2001, p. 7). Para isso, utiliza como objeto de estudo acadêmico a política internacional, definida como um conjunto de práticas, frequentemente envolvendo o uso da força efetiva ou ameaçada, por meio das quais os Estados se relacionam (FARO, 2001, p. 7).

As relações entre pessoas de comunidades distintas, envolvendo o uso da força, existiram desde os primórdios da história e entre os mais variados povos. Mas as relações entre comunidades distintas nem sempre existiram sob a forma de relações "estados territoriais" que formam um sistema de unidades concebidas como soberanas e iguais entre si. Essa forma de política é eminentemente moderna (FARO, 2001, p. 7).

\section{Soberania dos estados nacionais e constituição das fronteiras}

O Tratado de Westphália, de 1648, consolidou a tendência de territorialização da política (FARO, 2001, p. 7), ou seja, marcou a mudança da ordem política internacional, caracterizada, desde então, em uma sociedade de Estados, cada qual com autoridade política sobre um determinado território. Reconheceu-se a existência de Estados separados e soberanos, nos quais não haveria qualquer autoridade superior, estabelecendo condições de autonomia para unidades políticas, sem criar obrigações mútuas (FARO, 2001, p. 12).

Os princípios de Westphália de não intervenção e soberania mais até do que a territorialização da política, forneceram a base de sustentação ideológica da ordem internacional dos últimos séculos, prevalecendo em todo o direito internacional um sistema laico de Relações Internacionais, na medida em que deu origem à estrutura legal e política das relações inter-estatais modernas.

Durante a paz de cem anos houve um crescimento da democracia, entendida aqui como um regime político fundado, a princípio, na soberania popular, com acesso ao poder do Estado e na tentativa do respeito aos direitos humanos. Nesse sentido, a opinião pública passa a ser de grande valia aos interesses políticos. Isso contribuiu para abalar as estruturas da então ordem feudal/aristocrática vigente, ainda no contexto da paz de cem anos. Esperava-se que a expansão do direito 
internacional, inclusive com a imensa proliferação de tratados a partir da década de 1860, fosse suficiente para evitar uma grande conflagração, mas esse não foi o caso (FARO, 2001, p. 12).

A radicalização do sistema westphaliano, com caráter de vinculação territorial da política após a Segunda Guerra Mundial, a partir do qual um Estado deverá ter uma forma de governo própria, foi um processo lento. Esta vinculação foi melhor representada pelo Cap. XI da Carta das Nações Unidas, que se refere à auto-determinação dos povos e do direito a um território com soberania política correspondente.

De modo diverso, os regimes comunistas caminhavam na contramão deste princípio, já que a política externa stalinista acabou servindo de escudo à idéia da territorialização da política, visto que, neste regime, a soberania dos Estados anexados, bem como a política implementada em cada bloco, não estavam associadas a um território e não se submetiam à existência de fronteiras. Em cada bloco comunista, incluindo Estados que sempre buscaram uma maior autonomia em relação à Moscou (Iugoslávia, Tcheco-Eslováquia, etc), os poderes centrais se faziam exatamente pela firme adesão dos Estados nacionais a uma concepção de Estado que, como bloco histórico, não se submetia à fragmentação dos Estados Nacionais sob forma de soberania liberal democrática.

Do lado ocidental, vinculadas unicamente às determinações territoriais da política e da história das nações que abrigavam, as fronteiras dos diversos Estados, bem como os termos dos estatutos que as definiram, sofreram inúmeras modificações ao longo dos anos e acontecimentos posteriores aos acordos de Westphália.

De acordo com Ulf Hannerz (1997, p. 15), é nas regiões fronteiriças que as “coisas" acontecem, já que as fronteiras, na realidade, não imobilizam, são atravessadas. "Fluxo" sugere uma espécie de continuidade e passagem, "limites" têm a ver com descontinuidades e obstáculos. Segundo Grimson (2000), essas fronteiras inter-estatais, na maioria das vezes, não são naturais, nem necessariamente produtos de acordos históricos que surgiram de relações de forças entre os Estados e suas relações com as populações locais. As identificações diferenciadas que surgem e se negociam na fronteira se vinculam também aos interesses das populações locais e às suas necessidades de organização social. 
Tanto Estado quanto soberania constituem conceitos dinâmicos, e não estáticos, e é compreensível que eles acompanhem as mudanças estruturais dos sistemas políticos e econômicos internacionais. Fluxo, mobilidade, recombinação e emergência (HANNERZ, 1997, p. 15), tornaram-se temas preferenciais à medida que a globalização e a transnacionalidade passaram a fornecer os contextos da política internacional, confirmando a ideia de que os Estados nascem de práticas políticas e são construções históricas.

Pensar o fenômeno "fronteira" requer uma reflexão ampla que atenda a vários fatores colocados de modo imbricado e que faça parte das dinâmicas sociais de diferentes contextos. Dentro dessa teia, é primordial tratar os elementos constitutivos desse contexto, como a cultura, a identidade, as práticas definidas pelos grupos, a sua bagagem histórica, as suas bases econômicas, os seus marcos referenciais e a sua complexidade.

Fronteira, assim, pode ser analisada como um limite entre dois universos de regras, uma dicotomia acentuada entre as identidades: nós e os “outros”. Esses limites são fundados por marcas de oposições políticas, étnicas, linguísticas, culturais, etc. As fronteiras também possuem caráter de permeabilidade. Países fronteiriços são como vizinhos: todos definindo uma oposição, mas incapazes de viver sem a influência e a interferência do outro (MENDONÇA, 2005).

A ideia de fronteira assumiu um papel importante para os Estados ocidentais e suas políticas externas. É um processo historicamente ativo, devido a eventos que são reveladores das intensas transformações pelas quais vêm passando os países, a partir do que se observa o aumento das migrações e os problemas que isso acarreta. Contemporaneamente, os países adotam regras e legislações com enfoques diferenciados sobre direitos dos migrantes. É necessário a formulação de políticas públicas, pautadas pelo marco da proteção dos direitos humanos, por meio da incorporação das múltiplas dimensões da realidade migratória. No entanto, quando se trata de políticas migratórias, a condição de "cidadãos do mundo" (RIBEIRO, 2007) é colocada de lado.

As fronteiras territoriais confrontadas com as fronteiras da liberdade interagem com a tendência histórica de mobilidade humana, as políticas que pretendem administrar os movimentos populacionais contribuem, de maneira geral, 
para reforçar os "muros da nação" e a separação do "nós” em relação aos “outros”. A liberdade de locomoção restringe-se às fronteiras territoriais e políticas, além das econômicas (RIBEIRO, 2007, p. 7).

\title{
3 Migrações internacionais contemporâneas: um panorama geral
}

A administração política das fronteiras que separa o binômio "nós/outros" implica na aceitação do outro, da diferença. Os processos migratórios internacionais, uma tendência histórica da humanidade, começam a ser analisados no mundo contemporâneo, enquanto fenômeno complexo e multidimensional (RIBEIRO, 2007, p. 60).

Segundo Rodolfo Casillas R. (apud SILIÉ; SEGURA, 2001), professor e investigador da Facultad Latinoamericana de Ciencias Sociales (FLACSO/RD),

\begin{abstract}
La migración internacional es un proceso social presente en todas las sociedades contemporáneas y anteriores. Por otra parte, en las actuales circunstancias de desarrollo tecnológico $y$ de comunicación, los procesos migratorios internacionales involucran aspectos de soberanía de los estados por la facilidad de desplazamiento de volúmenes crecientes de personas; de identidades nacionales por los intercambios culturales, de lenguas e fenotipos; de política interna por la recomposición de las minorías nacionales en el conjunto del Estado-nación, entre otros efectos, más allá de los tradicionales aspectos vinculados a la economía y la migración en busca de asilo y de refugio. La agenda actual de los gobiernos se ha nutrido $y$ los temas de atención vinculados a la migración internacional se han vuelto más complejos y con implicaciones en distintos procesos sociales, locales e internacionales.
\end{abstract}

As disparidades nas áreas da democracia, da governança, dos direitos humanos e da segurança são apontadas como fatores determinantes para o desenvolvimento futuro das migrações internacionais. Em muitos Estados onde predominam altas taxas de desemprego, baixos rendimentos e elevados níveis de crescimento populacional, eles interagem com o "processo democrático frágil", "Estado de direito fraco" e "administração pública ineficiente". Em tais circunstâncias, as migrações são consideradas meios de fuga contra precárias condições econômicas e políticas e como busca de defesa no novo país contra a volatividade dos mercados, ainda mais agravada pela crise financeira internacional, as crises 
políticas, os conflitos armados, entre outros riscos a que estão expostas as populações (RIBEIRO, 2007, p. 14).

A radicalização da globalização econômica provoca a mobilidade humana, os migrantes constituem a dimensão problemática do processo de globalização, já que, na maioria das vezes, seus direitos fundamentais são ignorados. Seus deslocamentos são causados pelas desigualdades do sistema, que os priva de seus direitos fundamentais e a consequente exclusão no processo de desenvolvimento social.

A definição de fronteiras internas tem reflexos no privilegiamento de determinadas categorias de imigrantes, ou de certas nacionalidades. A definição dos indivíduos reconhecidos como cidadãos no âmbito dos países e a delimitação dos sujeitos detentores de direitos encontram respaldo, por conseguinte, nos interesses econômicos, políticos e demográficos dos Estados (RIBEIRO, 2007, p. 4).

Se as fronteiras nacionais e territoriais foram severamente controladas e guardadas pelos Estados em diversos momentos históricos, contemporaneamente imperativos sistêmicos e efeitos a partir de uma dinâmica econômica global, imprimem um novo caráter à mobilidade espacial de pessoas. As acentuadas desigualdades regionais, o crescimento de reservas de mão de obra proporcionalmente "baratas”, os crescentes conflitos localizados, a constituição de mercados integrados têm desenhado um panorama distintivo às migrações internacionais, colocando a problemática dos movimentos populacionais no centro das tensões mundiais, ao lado das lutas pelo avanço da conquista dos direitos e pelo reconhecimento da cidadania (PATARRA apud RIBEIRO, 2007).

As fronteiras da autonomia do indivíduo começam a entrelaçar-se com as fronteiras das constituições dos Estados. A ideia de Estado criou um núcleo central de poder. O Estado e o conceito de soberania fornecem o conteúdo concreto à sua existência, que supõe uma unidade ideal, vontade comum dos indivíduos. A soberania é o elemento que atribui coerência e legitimidade ao poder do Estado. Ela permite que os homens passem a viver circunscritos às leis e ao Estado, fundando o conceito de legitimidade política (RIBEIRO, 2007, p. 24).

O Estado só é soberano por completo e independente em assuntos internos e externos, dentro de seu território, delimitado por fronteiras. Por isso, insiste no fortalecimento de seus limites, enaltecendo seu poder e sua jurisdição. A 
organização política dos Estados é, portanto, elemento-chave da busca de soluções regionais para problemas domésticos e globais.

Os princípios de Westphália fizeram avançar a sociedade internacional em termos conceituais: a nova ordem era fruto de negociações, legitimava uma sociedade de Estados soberanos, enaltecia a associação e a aliança, mas não era ingênua a ponto de ignorar a existência de hierarquia e hegemonia entre Estados e a mobilidade da balança de poder (SARAIVA, 2001).

\section{Instrumentos internacionais de proteção dos direitos humanos}

A criação da Liga das Nações foi baseada na proposta de paz feita por Woodrow Wilson, presidente dos Estados Unidos, no período de 1912 a 1921 . Foi dele a idéia de criar um conjunto de propostas para incentivar a cooperação entre os Estados, manter a paz mundial e reorganizar as relações internacionais ao fim da Primeira Guerra Mundial, a partir dos “Quatorze pontos”. A mais ousada de todas essas propostas foi a do "ponto quatorze": a criação de uma associação de nações para o oferecimento de garantias mútuas de independência política de integridade territorial. Destarte, o resultado foi a "Liga das Nações", uma organização política inter-estatal permanente para a preservação da paz. A criação dessa organização acabou sendo incorporada ao Tratado de Versailles, de 1919, que pôs fim à Primeira Guerra Mundial. A Liga das Nações teve existência de 1920 a 1946 (FARO, 2001, p. 15).

A Liga, de fato, apresentou, desde sua origem, diversos problemas que a condenariam ao fracasso. Entre outros, pode-se citar a não participação dos Estados Unidos. Embora a ideia de participação tivesse partido do presidente Wilson, o Congresso norte-americano não aprovou o ingresso do país na Liga. Da mesma maneira, a União Soviética também não entrou na organização, uma vez que, no início da década de 1920, logo após a implementação do socialismo, a nação tinha entre seus projetos a exportação da revolução e a luta para levar o socialismo ao mundo todo. Só alguns anos mais tarde, em 1926, com as mudanças na política internacional da URSS, o país entrou na Liga das Nações. A própria Alemanha, a principal derrotada no conflito, alimentou um sentimento de humilhação nacional, que se transformou em uma das bases sociais do nazismo. Foi também no interior 
da Liga que se fundou a Corte Permanente de Justiça Internacional. A Corte é encarregada de decidir, de acordo com o direito internacional, as controvérsias de ordem jurídica entre os países do mundo.

A criação da Liga das Nações dava realidade a algumas das ideias difundidas nos "projetos de paz perpétua” do século XVIII e representou uma primeira tentativa concreta de mudança das práticas políticas típicas do modelo westphaliano. A esperança de Wilson era de que a cooperação internacional, por meio do direito internacional, repassado de um moralismo idealista, pudesse oferecer os meios para a manutenção da paz duradoura (FARO, 2001, p. 15). A radicalização da ordem westphaliana, após a Segunda Guerra Mundial em razão da ampliação cada vez mais poderosa da idéia de bloco, causada pela expansão da URSS por um lado e do nazismo alemão, por outro, pode também ser entendida, dentro de certos limites, como um projeto de contenção do comunismo, a fim de radicalizar a ordem internacional sob o conceito de soberania, contrária à formação de blocos comunistas.

O Sistema ONU foi o sucessor da Liga das Nações, que fracassou com seu objetivo maior de manter a paz. A corrida armamentista que teve início na Alemanha na década de 1930, era a evidência de que as nações não se submetiam aos ideais da organização e, ao mesmo tempo, um prenúncio da Segunda Guerra Mundial, que eclodiu em setembro de 1939. A partir do Sistema das Nações Unidas, a ênfase atual recaiu no estabelecimento de regras de construção de comportamentos e no incentivo de condutas de cooperação.

Desde o final da Segunda Guerra Mundial, as potências vencedoras, dando continuidade aos esforços de institucionalização da política internacional do período entre-guerras, desenvolveram um programa de construção de um complexo de organizações internacionais, dedicadas a promover a cooperação multilateral em diversas áreas. As principais dessas instituições foram a Organização das Nações unidas (ONU) e as múltiplas organizações e agências a ela relacionadas (FARO, 2001, p. 22).

O objetivo primordial da ONU é manter a paz consubstanciada por seus dois órgãos principais: o Conselho de Segurança, mantenedor da paz mundial e a Assembleia Geral, órgão das Nações Unidas que mais se incorporou à realidade 
internacional pós-colonial, a partir da qual todos os países podem deliberar, sobre os mais variados temas da agenda internacional, sobretudo na realização dos direitos do homem. Está calcada principalmente na defesa dos direitos humanos, no desenvolvimento e na segurança coletiva. Por meio da Carta das Nações Unidas, fica claro que a proteção dos Direitos Humanos internacionaliza-se e ultrapassa as fronteiras delimitadas pelo direito interno. Permanece explícito que os países devem evitar os flagelos da guerra.

No âmbito da ONU, desenvolveram-se desde sua criação instrumentos de proteção de direitos humanos, que configuram um sistema normativo internacional e universal desses direitos (GODINHO, 2006). Os instrumentos principais, além da Carta das Nações Unidas de 1945 que fazia menção explícita à igualdade de proteção, são: a Declaração Universal dos Direitos do Homem (1948), que reúne direitos e liberdades de diferentes categorias, que se complementam e traduzem, em conjunto, o ideal de dignidade humana, e outros instrumentos internacionais que sucederam, entre eles, o Pacto Internacional dos Direitos Civis e Políticos (1966), o Pacto Internacional de Direitos Econômicos, Sociais e Culturais (1966), o Pacto de São José da Costa Rica (1969) e a Declaração de Viena (1993).

A Declaração Universal dos Direitos do Homem de 1948 é composta de trinta artigos, além do preâmbulo, e constitui o primeiro instrumento geral de direitos humanos adotado por uma organização internacional. Esse efetivo marco histórico da proteção internacional dos direitos humanos pode ser analisado de duas formas distintas e complementares, que determinam a sua importância. Em primeiro lugar, a Declaração determina direitos pertencentes a todas as pessoas, independentemente de limitações como nacionalidade, cor, raça, sexo ou religião. Em segundo, a Declaração reúne direitos e liberdades de diferentes categorias, que se complementam e traduzem, em conjunto, o ideal da dignidade humana (GODINHO, 2006, p. 11).

Embora visasse internacionalizar o sistema de garantia de proteção dos direitos do homem, a Declaração não é de caráter obrigatório. No entanto, com o passar do tempo, em razão de costume internacional, tornou-se obrigação moral, refletida na incorporação de seus dispositivos a diversos tratados internacionais e nas constituições de diversos Estados. Os tratados de Direitos Humanos são 
irrevogáveis, ou seja, de caráter vinculante e obrigatório. São acordados mediante um consentimento entre as partes e a boa fé, sujeitos à punição se não forem cumpridos.

A partir de meados do século XX, com a Declaração Universal de Direitos Humanos, a ideia é de que homens e mulheres passem a ocupar um espaço que antes estava reservado apenas aos Estados, quando os indivíduos, "indistintamente", adquirem o estatuto de sujeitos do direito internacional. A partir desse marco, a comunidade internacional deveria assumir a realização dos direitos humanos como uma causa de interesse comum e do interesse de toda humanidade (RIBEIRO, 2007, p. 42).

O Pacto Internacional sobre os Direitos Civis e Políticos de 1966 é de caráter individual, exceto auto-determinação e proteção das minorias, que surge da proteção do indivíduo contra o poder coercitivo do Estado, impõe a obrigação imediata aos Estados de respeitarem e assegurarem os direitos proclamados. São auto-aplicáveis, determinando a exigibilidade legal. O Pacto Internacional sobre os Direitos Econômicos, Sociais e Culturais de 1966 possui caráter coletivo e nasce da concepção social na dignidade humana. Visa estabelecer sob formas de direitos as condições sociais, econômicas e culturais para a vida apropriada. Prevê uma implementação progressiva das obrigações no máximo de seus recursos disponíveis, isso quer dizer que é de natureza programática, sendo o resultado de medidas econômicas e técnicas do Estado, por meio de um planejamento efetivo, com o objetivo de alcançar a gradual concretização dos direitos.

Os pactos internacionais constituem o mais ambrangente catálago de direitos humanos hoje existente, de aplicação não automática, complementando e aprofundando muitos dos dispositivos da Declaração Universal de 1948. Enquanto no Pacto Internacional dos Direitos Civis e Políticos cria a obrigação estatal de "tomar as providências necessárias", inclusive de natureza legislativa, o Tratado referente aos Direitos Econômicos, Sociais e Culturais, prevê a adoção de medidas, tanto para esforço próprio como pela cooperação e assistência internacionais (WEIS, 1999). Esses dois pactos somente entraram em vigor em 1976 e foram ratificados pelo Brasil no ano de 1992. 
O Pacto de San José da Costa Rica, de 1969, é o texto fundamental do sistema regional americano de Direitos Humanos. Sua entrada em vigor ocorreu somente em 1978. Houve um fortalecimento da democracia e do Estado de Direito, momento em que a abordagem sobre democracia abrangeu sua interrelação com a totalidade dos direitos humanos: civis, políticos, econômicos, sociais e culturais (WEIS, 1999, p. 43). O Pacto indica a necessidade da adoção de medidas concretas pelo Estado a fim de garantir o pleno exercício daqueles direitos (WEIS, 1999, p. 100).

A Declaração de Viena adotada em 1993, subscrita por 171 Estados, endossa a universalidade e a indivisibilidade dos direitos humanos, revigorando o lastro de legitimidade da chamada concepção contemporânea de direitos humanos introduzida pela Declaração de 1948. Assim, a Declaração de Viena de 1993 estende, renova e amplia o consenso da universalidade e da indivisibilidade dos direitos humanos cujos preceitos devem se aplicar tanto aos direitos civis e políticos quanto aos direitos econômicos, sociais e culturais, caracterizada por objetivos muito mais amplos e sensíveis e afirma ainda a interdependência entre os valores dos direitos humanos, do desenvolvimento e da democracia (PIOVESAN, 2004), como forma de governo mais favorável para o respeito aos direitos e às liberdades fundamentais.

Os direitos humanos como tema global e a salvaguarda da democracia na jurisdição de cada Estado referem-se à "garantia efetiva”, não somente dos direitos políticos, mas sociais, econômicos, culturais e civis da população, como condição que confere legitimidade aos governantes no plano mundial (RIBEIRO, 2007, p. 44). Se no momento em que o homem foi declarado sujeito de direitos o ente expresso na Declaração de 1948 era um ser abstrato, "diluído como membro do povo", com a incorporação dos direitos à condição de cidadão, estes se tornam circunscritos à situação jurídica do indivíduo ao país. Na esfera prática, frente à concepção de cidadania atrelada ao conceito de nacionalidade, os direitos humanos permanecem sob a égide do Estado, definidos política e territorialmente (RIBEIRO, 2007, p. 155).

Os instrumentos normativos internacionais sobre direitos humanos, a partir da segunda metade do século XX, se multiplicaram juntamente com a intensificação das reflexões acerca das condições de vida dos homens em todo o 
mundo. Isso indica que o desafio atual em relação aos direitos humanos reside na garantia de sua proteção.

O respeito e o desrespeito a tais direitos ocorrem necessariamente dentro da órbita jurídica interna dos Estados. A ideia dessa proteção internacional afeta a concepção clássica de soberania, inspiradora do princípio da não-intervenção e base do sistema das Relações Internacionais desde o Tratado de Westphália de 1648 (ALVES, 2001).

Os direitos humanos desafiam os fundamentos modernos da soberania política. Os instrumentos internacionais de proteção aos direitos humanos apresentam natureza subsidiária, pois atuam como garantias adicionais de proteção após falharem os sistemas nacionais. A responsabilidade primária pela tutela dos direitos fundamentais continua no âmbito do Estado, mas pode ser transferido à comunidade internacional quando sua interferência se mostrar necessária para suprir omissões ou deficiências (ARAUJO, 2008).

À medida em que o indivíduo é considerado segundo distintivo de natureza jurídico-política que o vincula a determinado país, os preceitos constitucionais de que todos são iguais perante a lei, sem distinção de qualquer natureza tornam-se não menos que meros artifícios teóricos. A formulação dos direitos do homem, decorrente da gênese do modelo democrático, implica na ideia de igualdade de direito ou de direitos, não igualdade de fato. O reconhecimento da universalidade dos direitos humanos torna-se ficção, à medida que os sujeitos permanecem subordinados aos liames do Estado-nação à consequente condição jurídico-política que caracteriza o cidadão (RIBEIRO, 2007, p. 154).

\section{Considerações finais}

Tecer críticas acerca da mobilidade humana nas fronteiras, na perspectiva dos direitos humanos, possibilita ensejar sobrevida ao desejo de efetivar tais direitos, construir subsídios para a formulação de novas legislações, para a construção de um sistema internacional, a incrementar diálogos e avaliar governos, atitudes, intenções e propostas de democracia. Às políticas estatais de cada país cabe a definição de novas cidadanias e, por pressuposto, dos novos sujeitos de direito. No 
paradigma dos direitos humanos, surge o conceito de família humana, da família universal, e nessa dinâmica histórica das últimas décadas, construíram-se possibilidades e instituições admiráveis (IMDH, 2007). A pessoa que migra é tão plena de direitos como qualquer outro cidadão do país. Os Direitos Humanos começaram a ser pautados na perspectiva de dois grandes princípios: o da universalidade e o da indivisibilidade (IMDH, 2007). Dessa forma, todas as sociedades e as pessoas têm direitos iguais e o dever de ajudarem umas às outras, favorecendo a compreensão mútua, a cooperação e uma paz duradoura entre todos os povos.

Tanto a teoria como a prática dos direitos humanos têm por objetivo superar essas situações sociais em função de valores e normas, que assegurem a dignidade da pessoa humana. Direitos humanos seriam, assim, princípios que perpassariam diversas culturas e somente poderiam ser aceitos, como direitos, à medida que fossem aceitos por diferentes culturas e sistemas jurídicos (BARRETO, 2009).

As identidades deslocadas dos migrantes questionam a própria identidade dos Estados modernos, que costuma representar a nação como formada por um único povo, mesmo quando o processo de unificação nacional foi forjado com violência, em que uma determinada etnia conseguiu se sobrepor a outras. Cria-se, assim, o mito de uma suposta identidade monocultural que antecede a chegada dos migrantes e é por eles ameaçada (REFÚGIO..., 2007). A aceitação do "outro" constitui elemento essencial para a construção de identidades coletivas enfatizando a indeterminação do próprio sujeito.

Em certo sentido, é possível interpretar a xenofobia, tal como indica Hobsbawm, como um fenômeno mais ou menos universal. "O que se defende é a ideia do "nós" como um corpo de pessoas unidas por um número incontável de coisas e "termos" em comum de existência em que vivemos, e cuja paisagem nos é familiar e reconhecível. É a existência disso que fica ameaçada com a entrada do que vem de fora" (HOBSBAWN, 2000). A força dessa xenofobia é o medo do desconhecido, das "trevas" em que podemos cair quando desaparecem os marcos que parecem proporcionar uma delimitação objetiva, permanente e positiva de nosso pertencimento a uma comunidade. Pertencer, de preferência, a grupos com insígnias visíveis de seus membros e marcas de reconhecimento é mais importante do que nunca em sociedades em que tudo se combina para aquilo que liga os seres humanos em comunidades (HOBSBAWN, 2000, p. 281). 
No plano moral, a maioria dos países se define "contra a discriminação, as políticas xenófobas e o racismo”. Isso envolve até mesmo a adoção de algumas políticas, por vários Estados, para integrar, ao menos em parte, o imigrante. Entretanto, a complexidade no plano prático torna a realidade permeada de contradições (RIBEIRO, 2007, p. 76). Nessa premissa, os conflitos estariam alocados, de um lado, na tensão voltada para o processo de integração na sociedade receptora, e de outro, nos desafios colocados pela noção de homogeneidade do Estado-nação (RIBEIRO, 2007, p. 94).

"Eles são conhecidos como "não nós”, em geral pela cor ou por outros estigmas físicos, ou pela língua. A xenofobia nacional que se matiza de racismo é quase universal, ela se volta contra as pessoas estrangeiras, e não contra as importações culturais estrangeiras. A xenofobia parece estar se tornando a ideologia da massa. O que hoje une a humanidade é a negação do que a espécie humana tem em comum" (HOBSBAWM, 2000, p. 282).

\section{Abstract}

This article proposes a reflection on the constitution of the National States from the radicalization of the principles established in the Treaty of Westphalia (1648), related to the precepts of non-intervention and sovereignty, prevailing in the international law a secular system of International Relations . From these principles, we find that the State is completely sovereign and independent in home and foreign affairs within its territory, bounded by national borders. Therefore, stresses the strengthening of its limits, brings its power and jurisdiction. State and sovereignty as both concepts are dynamic, not static, and it is understandable that they follow the structural changes of international economic and political systems. In this way, is also considered the concept of international migration, from which the migrants compromise the dimension of the globalization process, since most of the time, their basic rights are ignored. The international protection of human rights have subsidiary nature, it act as additional guarantees of protection, after national systems fail.

Keywords: National States. Borders. International migration. Human Rights. 


\section{Referências}

ALVES, José Augusto Lindren. Relações internacionais e temas sociais: a década das conferências. Brasília: IBRI, 2001.

ARAUJO, Nadia de. Direito internacional privado: teoria e prática brasileira. Rio de Janeiro: Renovar, 2008.

BARRETO, Vicente. Universalismo, multiculturalismo e direitos humanos. Disponível em: <http://www.dhnet.org.br/direitos/textos/globalizacao_dh/ barretoglobal.html>. Acesso em: abr. 2009.

CERVO, Amado L.; BERVIAN, Pedro A. Metodologia científica. 5. ed. São Paulo: Prentice, 2002.

COX, Robert. Social forces, states and world orders: beyond international relations theory. In: KEOHANE, R. O. (Org.) Neorealism and its critics. New York: Columbia University, 1986.

FARO, Marcus de Castro. De Westphalia a Seattle: a teoria das relações internacionais em transição Cadernos do REL, Brasília, p. 5-66, 2001.

GODINHO, Fabiana de Oliveira. A proteção internacional dos direitos humanos. Belo Horizonte: Del Rey, 2006.

GRIMSON, Alejandro. Fronteras, naciones e identidades: la periferia como centro. Buenos Aires: Ciccus, 2000.

HANNERZ, Ulf. Fluxos, fronteiras, híbridos: palavras-chave da antropologia transnacional. Mana, Rio de Janeiro, v. 3, n. 1, abr. 1997. Disponível em: <http:// www.scielo.br/scielo.php?script=sci_arttext\&pid=S0104-93131997000100001>. Acesso em mar. 2009.

HOBSBAWN, Eric J. Etnia e nacionalismo na Europa de hoje. In: BALAKRISHNAN, Gopal; ANDERSON, Benedict (Org.). Um mapa da questão nacional. Rio de Janeiro: Contraponto, 2000.

MENDONÇA, Luciana de Andrade. Parques Nacionais do Iguaçu e Iguazú: uma fronteira ambientalista entre Brasil e Argentina In: OLIVEIRA, Roberto Cardoso de; BAINES, Stephen G. (Org.). Nacionalidade e etnicidade em fronteiras. Brasília: Universidade de Brasília, 2005. 
MILESI, Rosita; LACERDA, Rosane (Org.). Políticas Públicas para as migrações internacionais: migrantes e refugiados. Brasília: IMDH; ACNUR; CDHM/CD, 2007.

PATARRA, Neide. Migrações internacionais e integração econômica do Cone Sul: notas para discussão. In: SALES, Tereza; SALLES, Maria do Rosário (Org.). Políticas migratórias: América Latina, Brasil e brasileiros no exterior. São Paulo: Sumaré/DESP, 2002.

PIOVESAN, Flávia. Direitos sociais, econômicos e culturais e direitos civis e políticos. Sur, Revista Internacional de Direitos Humanos, São Paulo, v. 1, n. 1, 2004. Disponível em: <ttp://www.scielo.br/scielo.php?pid=S180664452004000100003\&script=sci_arttext >. Acesso em: abr. 2009.

REFÚGIO, migrações e cidadania. Brasília: ACNUR; IMDH, 2007. (Caderno de debates, 2).

RIBEIRO, Heloisa Mazzoccante. Política imigratória no Brasil contemporâneo: limites e desafios na relação entre direitos humanos, democracia e desenvolvimento. Dissertação (Mestrado Mestrado em Estudos comparados sobre as Américas)Universidades de Brasília, Brasília, 2007.

SARAIVA, José Flávio Sombra. Relações Internacionais: dois séculos de história: entre a preponderância européia e a emergência americano-soviética (1815-1974). Brasília: IBRI, 2001.

SILIÉ, Rubén; SEGURA Carlos. Hacia una nueva visión de la frontera y de las relaciones fronterizas. Santo Domingo: Búho, 2002.

WEIS, Carlos. Direitos humanos contemporâneos. São Paulo: Malheiros, 1999. 